\title{
DIVERSIDADE GENÉTICA ENTRE INDIVÍDUOS DE Spondias lutea L. PROCEDENTES DO BAIXO SÃO FRANCISCO SERGIPANO, POR MEIO DE MARCADORES RAPD ${ }^{1}$
}

\author{
Itamara Bomfim Gois², Robério Anastácio Ferreira ${ }^{3}$, Renata Silva-Mann ${ }^{4}$, Maria de Fátima Arrigoni Blank ${ }^{4}$
} e Elísio Marinho Santos Neto 5 .

\begin{abstract}
RESUMO - A recuperação de matas ciliares com mudas que apresentam o máximo de diversidade genética possível é de suma importância para a conservação das espécies. Assim, este estudo foi realizado com o objetivo de caracterizar geneticamente, por meio de marcadores RAPD, indivíduos de Spondias lutea L. (cajá), com a finalidade de elaborar estratégias de produção de sementes para a recuperação de mata ciliar. O estudo foi realizado em uma área de mata ciliar no Baixo São Francisco sergipano, onde foi coletado material foliar de 17 indivíduos para a análise de RAPD. A extração de DNA foi realizada por meio de tampão CTAB 2\%, e para a geração de polimorfismo foram empregados 17 oligonucleotídios. A matriz binária construída com presença (1) e ausência de bandas (0) foi usada para o cálculo da estimativa de similaridade genética e, a partir desta, foi feita a representação simplificada das similaridades, pelo método de agrupamento UPGMA, e a estabilidade dos agrupamentos foi testada pela análise "bootstrap". Para visualização da divergência entre os indivíduos, realizou-se o agrupamento dos indivíduos pelo método de Tocher. A matriz de distância genética foi comparada com a matriz de distância geográfica pelo teste de Mantel, com a finalidade de verificar se há correlação entre as mesmas. A similaridade genética média entre os indivíduos foi de $46,8 \%$, e a amplitude das similaridades variou de 21 a 78\%. Não houve associação entre as distâncias genéticas e geográficas $(r=0,08)$. Com o método de agrupamento de Tocher, houve a formação de cinco grupos e o valor mínimo de similaridade calculado, acima do qual os indivíduos são considerados geneticamente iguais, foi igual a 91\%. Assim, os indivíduos analisados são considerados divergentes e podem ser utilizados como matrizes porta-sementes em programas de produção de sementes para a recuperação de mata ciliar.
\end{abstract}

Palavras-chave: Produção de sementes; Fragmentação florestal; Recuperação de mata ciliar.

\section{GENETIC DIVERSITY AMONG INDIVIDUALS OF Spondias lutea $L$. ORIGINATING FROM SERGIPE LOW SAN FRANCISCO AREA USING RAPD MARKERS}

\begin{abstract}
The restoration of riparian forests with seedlings that have as much genetic diversity as possible is very important for the conservation of species. Thus, the objectives of this study were to characterize genetically, by RAPD markers, individuals of Spondias lutea $L$., and to elaborate strategies of seed production for restoration of riparian forest. The study was conducted in a riparian forest in the Low San Francisco area in Sergipe State, Brazil, where leaves of 17 individuals were collected for RAPD analysis. The DNA extraction was performed with CTAB $2 \%$ buffer and for the polymorphism generation 17 primers were used. We used a binary matrix constructed with presence (1) and absence (0) of bands in order to obtain the genetic similarity estimates.
\end{abstract}

\footnotetext{
${ }^{1}$ Recebido em 23.06.2008 aceito para publicação em 13.02.2014.

${ }^{2}$ Programa de Pós-Graduação em Fitotecnia, Universidade Federal de Viçosa, Viçosa, Brasil. E-mail: <itamarafloresta@gmail.com>. ${ }^{3}$ Departamento de Ciências Florestais, Universidade Federal de Sergipe, Centro de Ciências Agrárias Aplicadas, UFS, Brasil. E-mail:<raf@ufs.br>.

${ }^{4}$ Departamento de Engenharia Agronômica, Universidade Federal de Sergipe, Centro de Ciências Agrárias Aplicadas, UFS, Brasil.E-mail: <renatamann@gmail.com>e <fatima.blank@gmail.com>.

${ }^{5}$ Secretaria de Estado do Meio Ambiente e dos Recursos Hídricos de Sergipe/Secretaria de Biodiversidade e Florestas. E-mail: < elisio.santosneto@semarh.se.gov.br>.
} 
The simplified representation of the similarities was made by the UPGMA grouping method and stability of groupings was tested by bootstrap analysis. For the visualization of the divergence among individuals, we used the Tocher grouping method. The genetic distance matrix was compared with the matrix of geographical distance by Mantel's test, in order to determine whether a correlation exists between them. The mean genetic similarity between individuals was 46,8\%, with the similarity coefficients ranging from 21 to $78 \%$. There was no association between genetic and geographical distances $(r=0.08)$. Five groups were formed by the Tocher grouping method. The minimum value of calculated similarity was $91 \%$. Thus, the analyzed individuals were considered divergent and can be used as tree-seeds in seed production programs to restore riparian forests.

Keywords: Seed yield; Forest fragmentation; Riparian forest restoration.

\section{INTRODUÇÃO}

A espécie Spondias lutea L., conhecida como cajazeira, apresenta como centro de origem a América Tropical e encontra-se amplamente distribuída no Brasil (PINTO et al., 2003), onde é encontrada isolada ou agrupada, em regiões da Amazônia e da Mata Atlântica, prováveis zonas de dispersão da espécie. Pode também ser encontrada nas zonas mais úmidas dos Estados do Nordeste e de forma espontânea ou subespontânea em matas e campos de pastagens (SOUZA, 2000), onde regenera a partir de sementes ou vegetativamente. Devido a essa característica, é recomendada para reflorestamentos ecológicos (LORENZI, 1992).

A Mata Atlântica, representante de uma das mais complexas diversidades de espécies e altos índices de endemismo, encontra-se entre os biomas mais ameaçados, restando atualmente cerca de 7,91\%, ou seja, $102.012 \mathrm{~km}^{2}$ de sua cobertura original (SOS MATA ATLÂNTICA, 2009). Porém, o conhecimento deste bioma ainda é bastante incipiente, principalmente quanto à estruturação genética populacional de suas espécies, e procedimentos adequados de amostragem para fins conservacionistas e de manejo (MORAES et al., 1999). São raros os casos de espécies estudadas do ponto de vista genético, sendo estes indispensáveis à exploração racional, à recuperação e, principalmente, à conservação dos recursos da floresta tropical (KAWAGUICI; KAGEYAMA, 2001).

No papel de reconstrução de florestas, é importante que se mantenha o nível de diversidade genética encontrado nas populações naturais. Portanto, tornam-se necessários estudos dos padrões de distribuição da variabilidade genética que ocorrem nos fragmentos florestais. Saber como essa variabilidade está distribuída dentro das populações é de suma importância para que seus tamanhos não fiquem abaixo do mínimo viável, comprometendo a perpetuação da espécie (BOTREL; CARVALHO, 2004).

Os marcadores moleculares têm sido empregados frequentemente no estudo da diversidade e estrutura genética de populações, em que esta se refere à distribuição da variabilidade genética entre e dentro de populações. A formação da estrutura é resultante de fatores como sistema de acasalamento, níveis de endogamia, seleção natural ou artificial, fluxo gênico e deriva genética entre e dentro das populações (FERREIRA, 2003).

Uma forma muito eficaz de detectar a variabilidade genética é por meio do uso do marcador molecular RAPD (Polimorfismo de DNAAmplificado ao Acaso), um dos mais utilizados (FERREIRA; GRATTAPAGLIA, 1998). Entre as vantagens citadas para a técnica, podem-se destacar: simplicidade, rapidez, baixo custo, demanda de quantidades mínimas de DNA e, por utilizar primers de sequência arbitrária, é possível a realização de análises genéticas diretamente em nível de DNA sem a necessidade de conhecimento prévio da sequência do genoma da espécie a ser estudada (LACERDA et al., 2002).

Desde o surgimento da técnica em 1990, muitos estudos têm utilizado o RAPD na realização de análises genéticas com diferentes finalidades em diversos grupos taxonômicos de plantas, animais e microrganismos, visando não apenas à caracterização, como também a conservação das espécies (LACERDA et al., 2002). Para determinação da diversidade e da estrutura genética em populações naturais, diversos trabalhos têm utilizado essa técnica. Trindade e Chaves (2005) e Freire et al. (2007) comprovaram a sua eficiência estudando a estrutura 
genética de Eugenia dysenterica e Schizolobium parahyba, respectivamente.

Este trabalho foi realizado com o objetivo de caracterizar geneticamente, por meio de marcadores RAPD, indivíduos de Spondias lutea L. (cajá) procedentes da região do Baixo São Francisco sergipano, com a finalidade de elaborar estratégias de coleta de sementes para a recuperação de áreas degradadas.

\section{MATERIAL E MÉTODOS}

\subsection{Caracterização da área de estudo}

O estudo foi realizado em uma área de 100 ha (10 km de extensão/100 m de largura) de mata ciliar no Baixo São Francisco sergipano, entre os Municípios de Neópolis (10¹8'39"'S e 36 34'36"W) e Santana do São Francisco $\left(10^{\circ} 15^{\prime} 55^{\prime}\right.$ 'S e $\left.36^{\circ} 38^{\prime} 15^{\prime \prime} \mathrm{W}\right)$. Para este estudo, foram coletadas folhas de 17 indivíduos em estádio reprodutivo de Spondias lutea L. na área que é composta por 52 indivíduos. A amostragem foi do tipo aleatória simples e com o auxílio do Global Position System (GPS), modelo Garmin 12, e as coordenadas geográficas dos indivíduos foram marcadas. Todo o material coletado foi acondicionado em gaze e em saco plástico devidamente lacrado, identificado, mantido em caixa de isopor com gelo e transportado ao Laboratório de Cultura de Tecidos e Melhoramento Vegetal do Departamento de Engenharia Agronômica da Universidade Federal de Sergipe (DEA/ UFS), sendo armazenado em freezer a $-20{ }^{\circ} \mathrm{C}$ até o momento da extração.

\subsection{Extração de DNA}

A extração de DNA foi realizada de acordo com o protocolo descrito por Nienhuis et al. (1995), com modificações. Em um almofariz, cerca de $1 \mathrm{~g}$ de folhas jovens foi macerado com $5 \mathrm{~mL}$ de tampão de extração CTAB 2\% (Cetil Trimetil Brometo de Amônio) e $20 \mu \mathrm{L}$ de $\beta$-mercaptoetanol, para retardar a oxidação de metabólitos secundários. O material macerado foi levado ao banho-maria a $65^{\circ} \mathrm{C}$, por $60 \mathrm{~min}$.

Após esse período, $1.000 \mu \mathrm{L}$ de cada amostra foram colocados em tubos tipo eppendorf contendo $1.000 \mu \mathrm{L}$ de clorofórmio: álcool isoamílico. Os tubos foram agitados para obtenção de uma emulsão e, posteriormente, centrifugados a $7.000 \mathrm{rpm}$, por $30 \mathrm{~min}$. O sobrenadante foi pipetado, vertido em $1.000 \mu \mathrm{L}$ de álcool:acetato de amônio e condicionado no freezer $\left(-20^{\circ} \mathrm{C}\right)$ por no mínimo $1 \mathrm{~h}$, para precipitação dos ácidos nucleicos. Após a precipitação do DNA, as amostras foram centrifugadas a $14.000 \mathrm{rpm}$ por $10 \mathrm{~min}$, e ao precipitado foram adicionados $100 \mu \mathrm{L}$ de etanol, deixando-se $10 \mathrm{~min}$ em temperatura ambiente, quando se procedeu a uma nova centrifugação por $10 \mathrm{~min}$ a $4.000 \mathrm{rpm}$, sendo possível retirar o sobrenadante e secar o pellet. Em seguida, adicionaram-se $100 \mu \mathrm{L}$ de TE ( $1 \mathrm{mM}$ de Tris e $0,1 \mathrm{mM}$ de EDTA), para solubilização do DNA.

A quantificação do DNA extraído foi realizada em gel de agarose $1 \%$ em TBE 0,5 X. Alíquotas do DNA foram aplicadas nos poços do gel ao lado de uma série de concentrações conhecidas de DNA (20-200 ng), sendo a concentração das amostras estimada por comparação.

\subsection{Condições de amplificação do DNA genômico}

As reações de RAPD foram baseadas no método descrito por Williams et al. (1990). Foram empregados 17 oligonucleotídios para a geração de polimorfismo da marca Integrated DNA Technologies (IDT) (Tabela 1). As reações de amplificação foram conduzidas em termociclador Uniscience Biometra TPersonal, em um volume de $13 \mu \mathrm{L}$ contendo $2,92 \mu \mathrm{L}$ de água ultrapura; $1,30 \mu \mathrm{L}$ de tampão PCR 10X; $1 \mu \mathrm{L}$ de cloreto de magnésio $50 \mathrm{mM} ; 1,04 \mu \mathrm{L}$ de dNTP 2,5 mM; 1,04 $\mu \mathrm{L}$ de BSA (Soro Albumina Bovina); 0,2 $\mu \mathrm{L}$ da enzima Taq DNA polimerase; $2,5 \mu \mathrm{L}$ do oligonucleotídio iniciador e $3 \mu \mathrm{L}$ do DNA genômico. As reações foram submetidas a 45 ciclos de amplificação após a desnaturação inicial a $94{ }^{\circ} \mathrm{C}$, por 2 min. Cada ciclo constituiu-se de $15 \mathrm{seg}$ para desnaturação a $94^{\circ} \mathrm{C} ; 30$ seg para anelamento do iniciador a $42{ }^{\circ} \mathrm{C}$; e $30 \mathrm{seg}$ para a extensão a $72{ }^{\circ} \mathrm{C}$. Ao final dos 45 ciclos, foi realizada uma extensão final de $2 \mathrm{~min}$ a $72{ }^{\circ} \mathrm{C}$.

Os produtos da amplificação foram separados por eletroforese em cuba horizontal, utilizando-se gel de agarose $1 \%$ em tampão TBE 0,5 X (0,045 M Tris-borato e $0,001 \mathrm{M}$ de EDTA), a $100 \mathrm{~V}$ por $90 \mathrm{~min}$. Em seguida, o gel foi corado com brometo-de-etídio e os produtos da amplificação, visualizados sob luz ultravioleta.

\subsection{Análise de RAPD}

Nas avaliações visuais dos géis, a presença (1) e a ausência de bandas ( 0 ) foram usadas para a construção de uma matriz binária. As bandas que apresentaram coloração fraca e baixa definição foram descartadas. Com a matriz binária, calculou-se a porcentagem de

Revista Árvore, Viçosa-MG, v.38, n.2, p.261-269, 2014 
Tabela 1 - Oligonucleotídios utilizados e respectiva sequência de bases, número total de bandas observadas, número de bandas polimórficas e porcentagem de polimorfismo para 17 indivíduos de Spondias lutea L., em populações naturais na região do Baixo São Francisco sergipano.

Table 1 - Primers used and respective base sequences, total of bands, number of polymorphic bands and percentage of polymorphism for 17 individuals of Spondias lutea L., in natural populations in the Sergipe Low San Francisco area.

\begin{tabular}{|c|c|c|c|c|}
\hline Oligonu-cleotídeos & Seqüências & $\begin{array}{c}\text { Número total } \\
\text { de bandas }\end{array}$ & $\begin{array}{c}\text { Número de bandas } \\
\text { polimórficas }\end{array}$ & $\begin{array}{c}\text { Bandas } \\
\text { polimórficas (\%) }\end{array}$ \\
\hline IDT 1 & $5^{\prime} \mathrm{CAG}$ GCC CTT C 3' & 13 & 10 & 76,9 \\
\hline IDT 2 & 5' TGC CGA GCT G 3' & 8 & 3 & 37,5 \\
\hline IDT 3 & 5' GTT TCG CTC C 3' & 5 & 5 & 100,0 \\
\hline IDT 4 & 5' TGA TCC CTG G 3' & 7 & 7 & 100,0 \\
\hline IDT 6 & 5' GTG AGG CGT C 3' & 7 & 7 & 100,0 \\
\hline IDT 8 & 5' GGA CCC AAC C 3' & 10 & 7 & 70,0 \\
\hline IDT 9 & $5^{\prime}$ CCC AAG GTC C 3' & 5 & 4 & 80,0 \\
\hline IDT 10 & 5' GGT GCG GGA A 3' & 9 & 4 & 44,4 \\
\hline IDT 11 & 5' ACG GAT CCT G 3' & 10 & 7 & 70,0 \\
\hline IDT 12 & 5' GAG GAT CCC T 3' & 10 & 8 & 80,0 \\
\hline IDT 14 & 5' GGC ACT GAG G 3' & 8 & 3 & 37,5 \\
\hline IDT 15 & 5' GGT CGG AGA A 3' & 11 & 9 & 81,8 \\
\hline IDT 16 & 5' TCG GAC GTG A 3' & 8 & 7 & 87,5 \\
\hline IDT 17 & 5' ACC TGG ACA C 3' & 12 & 11 & 91,6 \\
\hline IDT 18 & 5'GGA GGA GAG G 3' & 8 & 3 & 37,5 \\
\hline IDT 19 & 5' CCC GGC ATA A 3' & 18 & 11 & 61,1 \\
\hline IDT 20 & 5' AAA GTT GGG A 3' & 5 & 4 & 80,0 \\
\hline TOTAL & & 154 & 111 & 72,08 \\
\hline
\end{tabular}

polimorfismo obtido com cada oligonucleotídio utilizado, por meio da fórmula $P=n b p / n b t \times 100$, em que $P=$ porcentagem de polimorfismo (ou taxa de polimorfismo); nbp e nbt número de bandas polimórficas e número de bandas total, respectivamente.

A estimativa de similaridade genética $\left(S g_{i j}\right)$, entre cada par de indivíduos de Spondias lutea L., foi calculada por meio do coeficiente de Jaccard, empregando o programa NTSYS pc2.1. (ROHLF, 2001). As similaridades obtidas foram calculadas, empregando-se a seguinte expressão: $S g_{i j}=a / a+b+c$, em que $a=$ número de casos em que ocorre a presença da banda em ambos os indivíduos, simultaneamente; $b=$ número de casos em que ocorre a presença da banda somente no indivíduo $i$; e $c=$ número de casos em que ocorre a presença da banda somente no indivíduo $j$.

Os erros associados a cada distância $\left(1-S g_{i j}\right)$ foram estimados segundo Skroch et al. (1992), pela seguinte expressão: $V=n \cdot d(1-d) / n-1$, em que $V=$ variância da distância genética de cada par de indivíduo; $n=$ número total de bandas utilizadas na estimativa da distância genética; e $d=$ distância genética de cada par de indivíduo. O erro-padrão foi estimado pela expressão $(V / n)^{1 / 2}$.
A representação simplificada das similaridades foi realizada pela construção de dendrogramas pelo método de agrupamento UPGMA (Unweighted PairGroup Method Arithmetic Average) (SNEATH; SOKAL, 1973), utilizando o programa NTSYS pc2.1 (ROHLF, 2001). A estabilidade dos agrupamentos foi testada pela análise Bootstrap, com 1.000 repetições, utilizando o programa Boot (COELHO, 2002).

Para visualização da divergência genética entre os indivíduos, realizou-se também o agrupamento dos indivíduos pelo método de Tocher, conforme citação de Rao (1952), utilizando o programa GENES (CRUZ, 2007). Esse método parte do princípio de que, a partir da matriz de dissimilaridade, é identificado o par de indivíduos mais próximos (com menor dissimilaridade), formando o grupo inicial. Em seguida, é avaliada a possibilidade de inclusão de novos indivíduos no grupo, adotando-se o critério de que a dissimilaridade média intragrupo é sempre inferior a qualquer dissimilaridade intergrupo.

Os indivíduos geneticamente diferentes foram identificados a partir da estimativa do valor mínimo de similaridade, valor acima do qual os indivíduos são considerados geneticamente iguais ( $\mathrm{Sgm})$. O Sgm foi 
estimado por meio do teste $\mathrm{t}(0,1 \%$ de probabilidade), utilizando-se a seguinte expressão (CASTANHEIRA, 2001): $S g m=\overline{1}-(t . S s g)$; em que t é o valor tabelado de t com n-2 graus de liberdade e $S s g$, o erro médio das comparações consideradas no dendrograma.

A matriz de distância genética foi comparada com a matriz de distância geográfica pelo teste de Mantel, com a finalidade de verificar se há correlação entre as mesmas.. O teste de Mantel foi realizado através do programa NTSYS pc2.1 (ROHLF, 2001), utilizando-se 1.000 permutações aleatórias. Com esse objetivo, a matriz de distâncias geográficas foi obtida estimando a distância geográfica em quilômetros $(\mathrm{km})$ entre todos os indivíduos usando o programa GPS TrackMaker (FERREIRA JÚNIOR, 2008).

\section{RESULTADOS}

Com a utilização de 17 oligonucleotídios para o estudo da divergência genética de cajá (Spondias lutea L.), foram geradas pelo menos três bandas polimórficas por oligonucleotídio entre os indivíduos (Tabela 1). No total, foram gerados 154 produtos de amplificação, com uma média de 9,06 fragmentos. Desses, $111(72,1 \%)$ foram polimórficos e $43(27,92 \%)$, monomórficos. Os oligonucleotídios que apresentaram maior número de bandas polimórficas foram: IDT17 e IDT19, com 11 bandas, enquanto o IDT2, o IDT14 e o IDT18 apresentaram o menor número, três bandas.

A partir dos 111 fragmentos polimórficos de RAPD obtidos, foi estimada uma matriz de similaridade genética, pelo método de Jaccard, relacionando todos os pares de indivíduos (Tabela 2). A similaridade genética média entre os indivíduos foi de $46,7 \%$, o erro-padrão médio foi de $4 \%$ e o coeficiente de similaridade variou de 21 a $78 \%$. Os indivíduos que se apresentaram mais semelhantes foram o $\mathrm{C} 2$ e o $\mathrm{C} 3(78 \% \pm 0,04)$ e os mais divergentes, $\mathrm{C} 1$ e $\mathrm{C} 16(21 \% \pm 0,04)$.

De acordo com o método de Tocher, foram formados cinco grupos (Tabela 3 ). O primeiro está representado pelos indivíduos $\mathrm{C} 1, \mathrm{C} 4, \mathrm{C} 5, \mathrm{C} 9$ e C13, o segundo pelos indivíduos $\mathrm{C} 2, \mathrm{C} 3, \mathrm{C} 6$ e C10, o terceiro por $\mathrm{C} 7$ e C16, o quarto por $\mathrm{C} 8$ e $\mathrm{C} 11$ e o quinto pelos indivíduos $\mathrm{C} 12$, $\mathrm{C} 14, \mathrm{C} 15$ e $\mathrm{C} 17$.

Posteriormente, também foi realizado o agrupamento dos indivíduos com base nos resultados de similaridade genética de Jaccard (Figura 1). Os valores de similaridade permitiram a divisão dos indivíduos em quatro grupos,

Tabela 2 - Matriz de similaridade genética de Jaccard (abaixo da diagonal) e erro-padrão estimado (acima da diagonal) entre 17 indivíduos de cajá (Spondias lutea L.), procedentes da região do Baixo São Francisco sergipano, analisados por meio de marcadores RAPD.

Table 2 - Jaccard's genetic similarity matrix (below the diagonal) and estimated standard error (above the diagonal) among the 17 individuals of Spondias Iutea L., originating from the Sergipe Low San Francisco area, analyzed with RAPD markers Baixo São Francisco sergipano, pelo método de Tocher, usando-se dados de similaridade de Jaccard.

\begin{tabular}{ccccccccccccccccccccc}
\hline Indivíduo & 1 & 2 & 3 & 4 & 5 & 6 & 7 & 8 & 9 & 10 & 11 & 12 & 13 & 14 & 15 & 16 & 17 \\
\hline 1 & & 0,04 & 0,04 & 0,04 & 0,04 & 0,04 & 0,04 & 0,04 & 0,04 & 0,04 & 0,04 & 0,04 & 0,04 & 0,04 & 0,04 & 0,04 & 0,04 \\
2 & 0,59 & & 0,04 & 0,04 & 0,04 & 0,04 & 0,04 & 0,04 & 0,04 & 0,04 & 0,04 & 0,04 & 0,04 & 0,04 & 0,04 & 0,04 & 0,04 \\
3 & 0,46 & 0,78 & & 0,04 & 0,04 & 0,04 & 0,04 & 0,04 & 0,04 & 0,04 & 0,04 & 0,04 & 0,04 & 0,04 & 0,04 & 0,04 & 0,04 \\
4 & 0,43 & 0,47 & 0,48 & & 0,04 & 0,04 & 0,04 & 0,04 & 0,04 & 0,04 & 0,04 & 0,04 & 0,04 & 0,04 & 0,04 & 0,04 & 0,04 \\
5 & 0,43 & 0,66 & 0,67 & 0,45 & & 0,04 & 0,04 & 0,04 & 0,04 & 0,04 & 0,04 & 0,04 & 0,04 & 0,04 & 0,04 & 0,04 & 0,04 \\
6 & 0,46 & 0,70 & 0,73 & 0,46 & 0,71 & & 0,04 & 0,04 & 0,04 & 0,04 & 0,04 & 0,04 & 0,04 & 0,04 & 0,04 & 0,04 & 0,04 \\
7 & 0,47 & 0,70 & 0,65 & 0,40 & 0,67 & 0,75 & & 0,04 & 0,04 & 0,04 & 0,04 & 0,04 & 0,04 & 0,04 & 0,04 & 0,04 & 0,04 \\
8 & 0,41 & 0,68 & 0,67 & 0,40 & 0,64 & 0,67 & 0,77 & & 0,04 & 0,04 & 0,04 & 0,04 & 0,04 & 0,04 & 0,04 & 0,04 & 0,04 \\
9 & 0,29 & 0,31 & 0,33 & 0,48 & 0,26 & 0,29 & 0,30 & 0,31 & & 0,04 & 0,04 & 0,04 & 0,04 & 0,04 & 0,04 & 0,04 & 0,04 \\
10 & 0,43 & 0,51 & 0,53 & 0,57 & 0,50 & 0,53 & 0,50 & 0,51 & 0,41 & & 0,04 & 0,04 & 0,04 & 0,04 & 0,04 & 0,04 & 0,04 \\
11 & 0,39 & 0,52 & 0,59 & 0,46 & 0,50 & 0,61 & 0,52 & 0,60 & 0,30 & 0,60 & & 0,04 & 0,04 & 0,04 & 0,04 & 0,04 & 0,04 \\
12 & 0,44 & 0,53 & 0,52 & 0,44 & 0,47 & 0,54 & 0,56 & 0,58 & 0,36 & 0,52 & 0,65 & & 0,04 & 0,04 & 0,04 & 0,04 & 0,04 \\
13 & 0,32 & 0,35 & 0,38 & 0,41 & 0,37 & 0,41 & 0,39 & 0,42 & 0,36 & 0,48 & 0,57 & 0,47 & & 0,04 & 0,04 & 0,04 & 0,04 \\
14 & 0,31 & 0,45 & 0,47 & 0,43 & 0,49 & 0,52 & 0,47 & 0,53 & 0,34 & 0,47 & 0,61 & 0,54 & 0,58 & & 0,04 & 0,04 & 0,04 \\
15 & 0,32 & 0,44 & 0,47 & 0,42 & 0,40 & 0,50 & 0,53 & 0,55 & 0,31 & 0,45 & 0,57 & 0,53 & 0,40 & 0,51 & & 0,04 & 0,04 \\
16 & 0,21 & 0,25 & 0,28 & 0,23 & 0,26 & 0,34 & 0,33 & 0,33 & 0,22 & 0,34 & 0,32 & 0,33 & 0,27 & 0,34 & 0,35 & & 0,04 \\
17 & 0,34 & 0,45 & 0,45 & 0,37 & 0,54 & 0,53 & 0,52 & 0,57 & 0,26 & 0,51 & 0,54 & 0,57 & 0,44 & 0,55 & 0,52 & 0,39 \\
\hline
\end{tabular}


Tabela 3 - Agrupamento dos indivíduos de Spondias lutea L., procedentes da Região do Baixo São Francisco sergipano pelo método de Tocher, usando dados de similaridade de Jaccard.

Table 3-Grouping of the Spondias Iutea L. individuals, originated from the Sergipe Low San Francisco by Tocher method, using the genetic similarity of

\begin{tabular}{cccccc}
\hline Grupo Jaccard. & \multicolumn{5}{c}{ Indivíduos } \\
\hline I & C1 & C4 & C5 & C9 & C13 \\
II & C2 & C3 & C6 & C10 \\
III & & C7 & C16 & \\
IV & & C8 & C11 & \\
V & C12 & C14 & C15 & C17 \\
\hline
\end{tabular}

utilizando-se como critério de corte a similaridade genética média de $43,6 \%$. O primeiro grupo foi composto pelo indivíduo $\mathrm{C} 1$, o segundo pelos indivíduos $\mathrm{C} 2$, C3, C4, C5, C6, C7, C8, C10, C11, C12, C13, C14, C15 e $\mathrm{C} 17$, o terceiro pelo indivíduo C9 e o quarto pelo indivíduo $\mathrm{C} 16$, com boa consistência entre os agrupamentos (Figura 1).

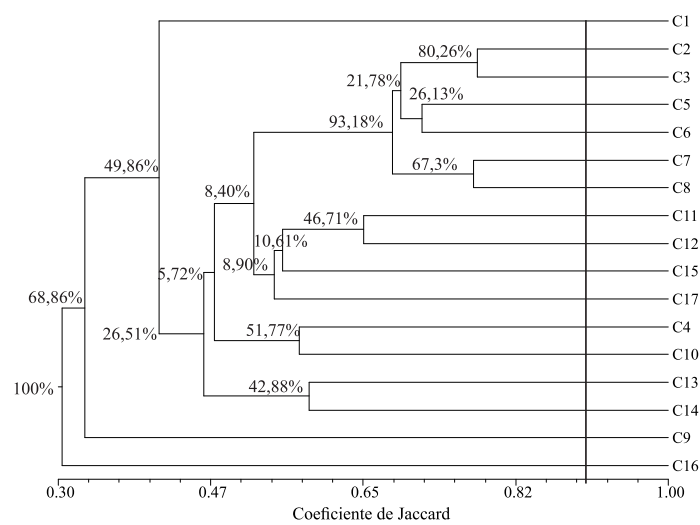

Figura 1-Similaridade genética entre 17 indivíduos de Spondias lutea L.procedentes da região do Baixo São Francisco sergipano, definida por meio do método de agrupamento de médias aritméticas não ponderadas (UPGMA), utilizando marcadores RAPD; linha de corte representando o valor mínimo de similaridade acima do qual os indivíduos são considerados geneticamente idênticos; e análise de Bootstrap.

Figure 1 - Genetic similarity among 17 individuals of Spondias lutea $L$. originated from the Sergipe Low San Francisco area, defined by the clustering unweighted pair group method with arithmetic mean (UPGMA), with RAPD markers; cut line representing the minimum value of similarity above which individuals are genetically identical and bootstrap analysis.
O valor mínimo de similaridade, valor acima do qual os indivíduos são considerados semelhantes, determinado por meio do teste de $\boldsymbol{t}$ a $0,1 \%$ de probabilidade, foi igual a 0,91 , indicando que não há indivíduos geneticamente iguais.

O teste de Mantel, usado para verificar a relação entre as distâncias genéticas e as distâncias geográficas, não apresentou resultado significativo $(\mathrm{p}=0,72)$, e o coeficiente de correlação entre as matrizes das distâncias foi baixo (0,078) (Figura 2).

\section{DISCUSSÃO}

Por meio da técnica RAPD, foi possível estimar a diversidade genética entre os indivíduos de Spondias lutea L. Diversos estudos têm sido realizados, confirmando a eficiência dessa técnica. Caixeta et al. (2003) observaram que a distância genética média entre genótipos de Eucalyptus spp. foi de 54\%, e a amplitude das distâncias variou de 24 a $73 \%$. Essas estimativas permitiram definir progenitores para geração de híbridos para futuros programas de melhoramento genético.

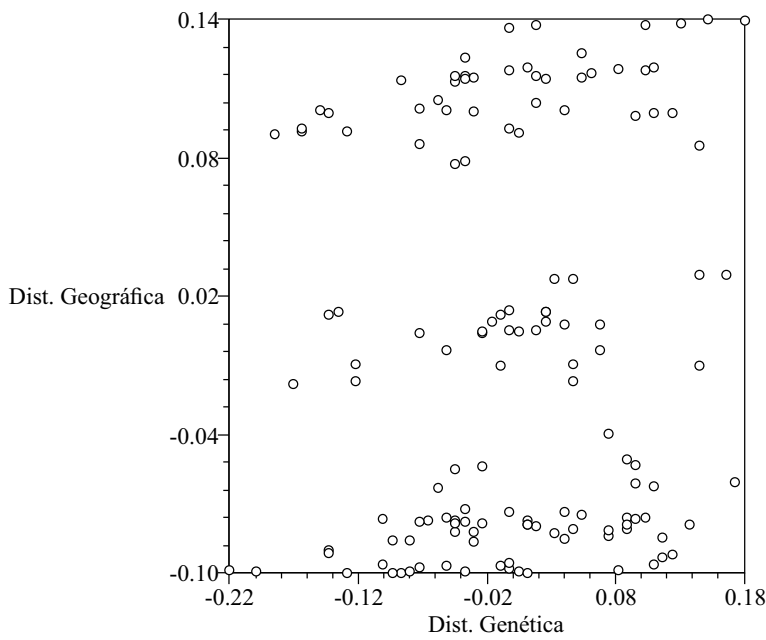

Figura 2 - Relação entre as distâncias genéticas (1-Sg $\left.g_{i j}\right)$ e as distâncias geográficas dos 17 indivíduos de Spondias lutea L. analisados. O coeficiente de correlação foi $0,078(\mathrm{p}=0,72)$.

Figure 2 - Relationship between genetic distance (1-Sg $\left.g_{i j}\right)$ and geographical distance of the 17 individuals of Spondias lutea L.assessed. The correlation coefficient was 0.078 ( $p=0.72)$. 
O alto grau de polimorfismo observado $(72,1 \%)$ indica que os genótipos estudados apresentam elevada diversidade genética. Oliveira et al. (2007), utilizando 28 oligonucleotídios, caracterizaram a diversidade genética entre acessos de Euterpe oleracea e obtiveram uma média de 9,4 bandas, resultado próximo ao encontrado neste estudo $(9,06)$. Bicalho (2006), avaliando a variabilidade genética de clones de Hevea sp. e usando 19 oligonucleotídios, obteve uma média de 6,3 fragmentos. Esse resultado foi semelhante também ao encontrado por Freire et al. (2007), estudando cinco populações de Schizolobium parahyba, em que utilizaram cinco oligonucleotídios e obtiveram uma média de 6,4 bandas.

A espécie estudada é utilizada em programas de restauração de áreas degradadas na Região do Baixo São Francisco sergipano, tornando imprescindível a seleção de árvores-matriz para iniciar um programa de colheita de sementes. Um dos critérios utilizados para a escolha dessas matrizes é a seleção de indivíduos mais divergentes geneticamente, visando à manutenção das populações das espécies que são inseridas nas áreas degradadas.

O método de agrupamento de Tocher possibilitou a divisão dos 17 indivíduos em cinco grupos, demonstrando a ampla variabilidade entre os indivíduos avaliados (ARAÚJO et al., 2002). O agrupamento baseado nos valores de similaridade genética de Jaccard possibilitou a formação de quatro grupos, porém o que chamou atenção foi o fato de que mais de $80 \%$ dos indivíduos foram agrupados no segundo grupo, o que permite inferir que, embora divergentes, os indivíduos apresentam certo parentesco. O fluxo gênico esperado para espécies pertencentes ao grupo ecológico das secundárias, como a Spondias lutea, provavelmente é o intermediário (KAGEYAMA et al., 2003), o que pode explicar o agrupamento formado pela maioria dos indivíduos analisados, uma vez que têm indivíduos com cerca de $8 \mathrm{~km}$ de distância entre si.

O valor mínimo de similaridade $(0,91)$ é o valor acima do qual os indivíduos são considerados geneticamente iguais (CASTANHEIRA, 2001), observando-se, mais uma vez, que os indivíduos analisados são divergentes.

Segundo Nienhuis et al. (1995), a partir de 100 bandas, praticamente ocorre uma estabilização do coeficiente de variação das similaridades genéticas entre os genótipos. Analisando os resultados do "Bootstrap", observou-se um bom grau de consistência dos agrupamentos (Figura 1). Assim, os fragmentos polimórficos utilizados foram considerados suficientes para a avaliação da diversidade genética de Spondias lutea, procedente da região do Baixo São Francisco sergipano, sendo recomendada a utilização de marcadores codominantes, como os microssatélites, para confirmar os resultados.

Observa-se que as espécies que não são domesticadas apresentam elevado polimorfismo em um número reduzido de oligonucleotídios. Estopa et al. (2006), estudando a divergência genética entre indivíduos de Eremanthus erythropappus e utilizando 10 oligonucleotídios, obtiveram 56 fragmentos polimórficos, o que foi suficiente para estimar a variabilidade genética entre os indivíduos. Bessega et al. (2000), utilizando quatro oligonucleotídios, obtiveram 46 bandas, que foram suficientes para determinar a diversidade genética entre indivíduos de Prosopis glandulosa e P. velutina.

O teste de Mantel aplicado revelou ausência de correlação entre a matriz de distância genética e a matriz de distância geográfica. O coeficiente de correlação $(0,078)$ entre as distâncias genéticas e a distância geográfica foi baixo e não significativo, demonstrando que a diversidade genética entre os indivíduos não pode ser explicada pela distância geográfica entre os mesmos, sendo a deriva genética a causa mais provável (SOUZA et al., 2004).

\section{CONCLUSÕES}

1. Os fragmentos polimórficos utilizados no estudo foram considerados suficientes para a análise da diversidade genética de cajá (Spondias lutea L.), procedente da Região do Baixo São Francisco sergipano.

2. Fenômenos como a deriva genética podem estar ocorrendo na área devido ao processo de fragmentação florestal.

2. O valor mínimo de similaridade é igual a $91 \%$; assim, todos os indivíduos analisados são divergentes e podem ser utilizados como matrizes porta-sementes em programas de produção de sementes para a recuperação de Mata Ciliar na região do Baixo São Francisco sergipano.

Revista Árvore, Viçosa-MG, v.38, n.2, p.261-269, 2014 


\section{REFERÊNCIAS}

ARAÚJO, D. G.; CARVALHO, S. P.; ALVES, R. M. Divergência genética entre clones de cupuaçuzeiro (Theobroma grandiflorum WILLD EX SPRENG SCHUM). Ciência e

Agrotecnologia, v.26, n.1, p.13-21, 2002.

BESSEGA, C.; SAIDMAN, B. O.; VILARDI, J. C. Isozyme and RAPD studies in Prosopis glandulosa and P. velutina (Leguminosae, Mimosoideae). Genetics and Molecular Biology, v.23, n.3, p.639-648, 2000.

BICALHO, K. C. Identidade genética entre clones de seringueira Hevea spp. de diferentes procedências, baseada em marcadores RAPD. 2006. 66f. Dissertação (Mestrado em Agronomia) - Universidade Federal de Lavras, Lavras, MG, 2006.

BOTREL, M. C.; CARVALHO, D. Variabilidade isoenzimática em populações naturais de jacarandá paulista (Machaerium villosum Vog.), Revista Brasileira de Botânica, v.27, n.4, p.621-627, 2004.

CAIXETA, R. P. et al. Variações genéticas em populações de Eucalyptus spp. detectadas por meio de marcadores moleculares. Revista Árvore, v.27, n.3, p.357-363, 2003.

\section{CASTANHEIRA, A. L. M. Marcadores} RAPD na avaliação do potencial de métodos de condução de população segregante de feijão. 2001. 76f. Dissertação (Mestrado em Genética e Melhoramento de Plantas) - Universidade Federal de Lavras, Lavras, 2001.

COELhO, A. S. BoodP Avaliação dos erros associados a estimativas de distância/ similaridades através do procedimento de bootrap com número de variáveis de marcadores (software). Goiânia: Universidade Federal de Goiás, Instituto de Ciências Biológica, Laboratório de Genética Vegetal, 2002.

CRUZ, C. D. Genes versão 2007: Aplicativo computacional em genética e estatística. Viçosa, MG: Universidade Federal de Viçosa, 2007.
ESTOPA, R. A. et al. Diversidade genética em populações naturais de candeia (Eremanthus erythropappus (DC.) MacLeish). Scientia Forestalis, n.70, p.97-106, 2006.

FERREIRA, M. E.; GRATTAPAGLIA, D.

Introdução ao uso de marcadores moleculares em análise genética. 3.ed. ${ }^{\circ}$ Brasília: Embrapa-Cenargen, 1998. p.220.

FERREIRA, M. A. J. F. Utilização das técnicas de marcadores moleculares na genética de populações, na genética quantitativa e no melhoramento de plantas. Boa Vista: Embrapa Roraima, 2003. 63p. (Documentos, 1)

FERREIRA JÚNIOR, O. GPS TrackMacker. Belo Horizonte: 2008. 176p.

FREIRE, J. M. et al. Estrutura genética de populações de Schizolobium parahyba (Vell.) Blake (guapuruvu) por meio de marcadores RAPD. Scientia Forestalis, n.74, p.27-35, 2007.

KAGEYAMA, P. Y. et al. Diversidade genética em espécies arbóreas tropicais de diferentes estágios sucessionais por marcadores genéticos.

Scientia Forestalis, n.64, p.93-107, 2003.

KAWAGUICI, C. B.; KAGEYAMA, P. Y.

Diversidade genética de três grupos de indivíduos (adultos, jovens e plântulas) de Calophyllum brasiliense em uma população de mata de galeria. Scientia Forestalis, n.59, p.131-143, 2001.

LACERDA, D. R. et al. A técnica de RAPD: uma ferramenta molecular em estudos de conservação de plantas, Lundiana, v.3, n.2, p.87-92, 2002.

LORENZI, H. Árvores brasileiras: manual de identificação e cultivo de plantas arbóreas nativas do Brasil. Nova Odessa: Plantarum, 1992. 384p

MORAES, P. L. R.; MONTEIRO, R.; VENCOVSKY, R. Conservação genética de populações de Cryptocarya moschata Nees (Lauraceae) na Mata Atlântica do estado de São Paulo. Revista Brasileira de Botânica, v.22, n.2, p.237-248, 1999.

NIENHUIS, J. et al. Genetic relationships among cultivars and lines of lima bean (Phaseolus lunatus L.) as measured by RAPD markers. Journal of the American Society for Horticultural Science, v.120, n.2, p.300-306, 1995. 
OLIVEIRA, M. S. P. et al. Diversidade genética entre acessos de açaizeiro baseada em marcadores RAPD. Ciência e Agrotecnologia, v.31, n.6, p.1645-1653, 2007.

PINTO, W. S. et al. Caracterização física, físicoquímica e química de frutos de genótipos de cajazeiras. Pesquisa Agropecuária Brasileira, v.38, n.9, p.1059-1066, 2003.

RAO, R. C. Advanced statistical methods in biometrical research. New York: John Willey and Sons, 1952. 390p.

ROHLF, F. J. Numerical taxonomy and multivariate analysis system. New York: 2001.

SKROCH, P. W.; TIVANG, J.; NIENHUIS, J. Analysis of genetic relationship using RAPD marker data. In: IUFRO INTERNATIONAL CONFERENCE: "Breeding tropical trees" Section 202-208, 1992, Cali. Proceedings... Cali: 1992. p.26-30.

SNEATH, P. H.; SOKAL, R. R. Numerical Taxonomy: the principles and practice of numerical classification. San Francisco: W. H. Freeman, 1973.
Sos mata ATlanticA. Atlas dos remanescentes florestais da Mata Atlântica - Período 2005 - 2008. São Paulo: 2009. Disponível em: http://mapas.sosma.org.br/ site_media/download/atlas\%20mata\%20atlanticarelatorio2005-2008.pdf

SOUZA, F. X. Efeito do porta-enxerto e do método de enxertia na formação de mudas de cajazeira (Spondias mombin L.). Revista Brasileira de Fruticultura, v.22, n.2. p.286-290, 2000.

SOUZA, L. M. F. I.; KAGEYAMA, P. Y; SEBBEN, A. M. Estrutura genética em populações fragmentadas de Chorisia speciosa St. Hil (Bombacaceae). Scientia Forestalis, n.65, p.70-79, 2004.

TRINDADE, M. G.; CHAVES, L. J. Genetic structure of natural Eugenia dysenterica DC (Myrtaceae) populations in northeastern Goiás, Brazil, accessed by morphological traits and RAPD markers. Genetics and Molecular Biology, v.28, n.3, p.407-413, 2005.

WILLAMS, J. G. K. et al. DNA polymorphisms amplified by arbitrary primers are useful as genetic markers. Nucleic Acids Research, v.18, n.22, p.6531-6535, 1990. 
